\title{
The Context of This Issue
}

\author{
F. GERALD KLINE \\ University of Michigan
}

When this project was originally conceived, we decided to focus our attention on research that was being done in a variety of cultures. It seemed necessary to examine the distinctive differences that associate with mass media presentations as well as youth groups in diverse cultural settings if we were to offset the narrowness of empirical and theoretical focus that accrues with studies done in only a "Western" setting-in particular, the American setting. There was also a strong concern for assembling the articles for this issue around research that derived from a concern for theory-building. Much of the media research has been descriptive, emphasizing prediction and showing little or no concern for explanation. Needless to say, as one can see from scanning the list of authors and their institutional affiliations, we did not succeed in our goal of making this an issue of comparative research. We think we have done a better job in finding relevant research that has a theoretical focus or has the potential for moving in that direction.

There are reasons for the problems that we found in trying to reach our goals. Although there is much research being done in the area of the mass media, little devotes itself exclusively to youth use. Despite the sudden surge of interest in the effects of violence in the media, we found that this is an area which has had little sustained empirical research. Major work by 
Schramm et al. (1961); Himmelweit et al. (1958); and Maccoby (1951, 1954) has had only sporadic follow-up. And this has been the case to an even greater degree in areas outside of Britain and the United States.

Another problem which has beset us in attempting to reach our goal is the way in which mass communication research has evolved. As my coeditor points out, much of the work has been done in sociology and psychology, with concern for integrating the findings into the more general aspects of those fields. Studies done within the narrower confines of "mass communication research" have only recently started to encompass a broader social science approach. Thus on the one hand we have findings that are relevant but separate from a comprehensive theoretical approach, and on the other, findings that are interesting but possibly spurious given the narrowness of view. The articles presented here make an attempt at moving toward a middle ground.

Very recently I attended the International Sociological Association meetings in Varna, Bulgaria, to make contact with those researchers from different parts of the world who have a common interest in youth and the mass media. It was a frustrating set of meetings from a number of perspectives. Ideologically there were great differences which prevented a true dialogue from taking place. Secondly, the amount and kind of research being undertaken was reminiscent of past experiences in some of the Western countries with a strong empirical tradition. One common characteristic, however, was a concern with what youth ought to be doing and what kind of media presentations were best for them. There was a ring of inevitability here which, in all probability, added to my frustrations.

Needless to say, though, the developments of the last decade in all parts of the world have accelerated interest in the area we have chosen to deal with in this issue. The massive growth in media technology and, to some observers, the concomitant growth in youth rebellion have produced a sense of urgency that one can easily discern in countries of differing ideological persuasion.

We hope this issue will spur a renewal of interest in this area for the social science disciplines. Socialization as it relates to the development of mass media use patterns; the reciprocal effect of mass media use in overall socialization; exploration of why certain media preferences exist at differing points in the adolescent life cycle; behavioral outcomes as a consequence of media use either separately or in conjunction with other informational inputs; and institutional responses to the pursuit of certain kinds of content are only a few areas that can benefit from further research. If we are to have a better understanding of how the mass media 
operate in the overall social context, it behooves us to examine it in the developmental process that is youth.

\section{REFERENCES}

SCHRAMM, W., J. LYLE, and E. PARKER (1961) Television in the Lives of Our Children. Palo Alto: Stanford Univ. Press.

HIMMELWEIT, H., A. OPPENHEIM, and P. VINCE (1958) Television and the Child. London: Oxford Univ. Press.

MACCOBY, E. (1954) "Why do children watch television." Public Opinion Q. 18 (Fall): 232-244.

- (1951) "Television: its impact on school children." Public Opinion Q. 15 (Fall): $421-444$. 